\title{
'A STUDY TO ASSESS THE AWARENESS \& FACTORS AFFECTING ACCEPTANCE OF PPIUCD IN SELECTED HOSPITAL OF DADRA \& NAGAR HAVELI'
}

Kaveriben Pandya*

\section{Bincy Mathew}

Associate Professor, Department of Obstetrics \& Gynecological Nursing, Shri Vinoba Bhave College of Nursing, Silvassa, D\&NH-*Corresponding Author

Tutor, Department of Obstetrics \& Gynecological Nursing, Shri Vinoba Bhave College of Nursing, Silvassa, D\&NH-

\section{Dr.V.K.Das}

Director, Medical \& Health Services, D\&NH \& DD

ABSTRACT Background: Population explosion is one of the major problems in India. It is a result of prevailing high birth rates and unmet need of birth controlling methods. The Government of India under National Health Mission has taken an initiative to provide PPIUCD in immediate postpartum period. In spite of several training programmes \& awareness activities across the country, the acceptance \& utilization of PPIUCD is very low. Hence, this study was conducted to determine proportion of women accepting PPIUCD \& describe the factors affecting acceptability \& non-acceptance of PPIUCD in selected hospital of DNH. Method: It was an exploratory study conducted at Shri Vinoba Bhave Civil Hospital, Silvasssa from January to February 2020. The sample size of the study was 90. The data was collected under 1)Antenatal mothers with term pregnancies 2)Immediate postnatal mothers delivered normally 3)Immediate postnatal mothers delivered through CS. Thirty(30) samples were selected in each category using convenient sampling technique. Result: The awareness about PPIUCD was only $23.33 \%$. The acceptance rate of PPIUCD was very low (22.22\%). The most common reasons for nonacceptance were (i) refusal from relatives \&(ii) refusal from husband, (iii) prefer natural method of contraception, (iv) religious belief among Muslim women, (v) fear of obesity \& (vi) lack of experience of PPIUCD. Conclusion: The emerging factors for less acceptance of PPIUCD are low literacy rate among women of DNH \& infrequent counseling \& education during antenatal period. Integration of a PPIUCD counseling service at every delivery point with provision of couple counseling can improve the success of this programme.

\section{KEYWORDS : Awareness, Acceptance, PPIUCD}

\section{INTRODUCTION:}

India accommodate about $16 \%$ of the world population, the second most populous country in the world, next to China. The rate of population growth continues unabated. Increasing number of births has got a deleterious effect on the health of the mother \& the child and hinders social \& economic upliftment of the family. High parity with very less gap between two pregnancies is also related to increased maternal, perinatal \& infant deaths and is associated with various obstetric \& gynecological complications \& nutritional problems. Hence, population control by appropriate method of family planning is necessary.

In spite of availability of wide range of contraceptives, the unmet need for family planning is estimated to be $13 \%$ (NFHS3 ). Among the various methods of family planning available for a woman, the Postpartum Intrauterine Contraceptive Device is the only method for couples requesting highly effective, inexpensive, reliable, non-hormonal, immediately reversible \& long acting contraceptive that can be initiated during the immediate postpartum period \& has no negative effect on lactation. The couple need not to return back to health providers after delivery \& has been protected before they assume sexual activity.

It is not only advantageous to the women \& couples; even the service provider's benefit from PPIUCD insertion as pregnancy is definitely ruled out, time is saved as it is performed on the same delivery table \& takes only 10-15 minutes for insertion.

The Ministry of Health \& Family Welfare, India under National Health Mission has taken initiative to provide PPIUCD facilities at every delivery point of all the government health facilities. Even several training programs \& awareness camps are conducted by NHM for health service providers \& also for the public.

Despite making contraceptives widely available, there is poor acceptance of contraceptive methods. Hence a study is undertaken to assess the awareness \& factors affecting acceptance of PPIUCD in selected hospital of Dadra \& Nagar Haveli.

\section{OBJECTIVES}

1. To determine proportion of women accepting PPIUCD in selected hospital of Dadra \& Nagar Haveli

2. To describe the factors affecting acceptability \& non acceptance of PPIUCD in selected hospital of Dadra \& Nagar Haveli

\section{METHOD}

Study Design \& Setting

It was an explorative study conducted at Shri Vinoba Bhave Civil Hospital, Silvasssa, Dadra \& Nagar Haveli from January to February 2020. It is 500 bedded tertiary care Govt. Teaching Hospital attached with a Govt Medical College at Silvassa. Here, all types of family planning services are provided free of cost under the various government schemes/programmes.

\section{Study Population}

All antenatal mothers with term pregnancies, all immediate postnatal mothers delivered normally \& all immediate postnatal mothers delivered through Caesarean Section in the same hospital during the time framework of the study were included in the study

\section{Sample Size and Sampling Technique}

The sample size of the study was 90 . The data was collected under three categories i.e.

1) Antenatal mothers with term pregnancies

2) Immediate postnatal mothers delivered normally

3) Immediate postnatal mothers delivered through caesarean section

Total 30 samples were selected in each category using convenient sampling technique. 
Tool \& Data Collection

A Structured Questionnaire was prepared. It was divided into three sections. Section 1 includes basic demographic variables i.e. age, education, occupation, socio economic status \& parity. Section 2 contains questions related to awareness regarding PPIUCD. The counseling \& education related to PPIUCD, its advantages - disadvantages were given to all the samples on first day of meeting. Data related to
Section 3 was collected on next day (Day 2) of their meeting which includes questions related to readiness for acceptance and reasons for non- acceptance. The data was collected using Structured Interview Scheduled method.

\section{RESULTS:}

The data collected were checked for completeness and were analyzed using descriptive statistics.

Table 1: Demographic Variables

\begin{tabular}{|c|c|c|c|c|c|c|c|c|c|}
\hline \multirow{2}{*}{\begin{tabular}{|l|} 
Sr. \\
No.
\end{tabular}} & \multirow[t]{2}{*}{ Variable } & \multicolumn{2}{|c|}{ Antenatal mothers } & \multicolumn{2}{|c|}{$\begin{array}{l}\text { Post natal mothers } \\
\text { undergone normal delivery }\end{array}$} & \multicolumn{2}{|c|}{$\begin{array}{l}\text { Post natal mothers } \\
\text { undergone LSCS }\end{array}$} & \multicolumn{2}{|l|}{ Total } \\
\hline & & $\mathrm{n}=30$ & $\%$ & $\mathrm{n}=30$ & $\%$ & $\mathrm{n}=30$ & $\%$ & $\mathrm{n}=90$ & $\%$ \\
\hline & \multicolumn{9}{|l|}{ Age in years } \\
\hline & $\leq 19$ & 0 & 0 & 0 & 0 & 8 & 26.67 & 8 & 8.88 \\
\hline & $20-24$ & 18 & 60 & 14 & 46.67 & 10 & 33.33 & 42 & 46.67 \\
\hline & $25-29$ & 10 & 33.33 & 6 & 20 & 7 & 23.33 & 23 & 25.56 \\
\hline & $>30$ & 2 & 6.67 & 10 & 33.33 & 5 & 16.67 & 17 & 18.89 \\
\hline \multirow[t]{7}{*}{2} & \multicolumn{9}{|l|}{ Education of mothers } \\
\hline & Graduate or Post graduate & 2 & 6.67 & 4 & 13.33 & 0 & 0 & 6 & 6.66 \\
\hline & Intermediate or diploma & 0 & 0 & 0 & 0 & 0 & 0 & 0 & 0 \\
\hline & High school certificate & 7 & 23.3 & 2 & 6.667 & 12 & 40 & 21 & 23.33 \\
\hline & Middle school certificate & 14 & 46.7 & 12 & 40 & 14 & 46.67 & 40 & 44.44 \\
\hline & Primary school certificate & 4 & 13.3 & 6 & 20 & 4 & 13.33 & 14 & 15.56 \\
\hline & Illiterate & 3 & 10 & 6 & 20 & 0 & 0 & 9 & 10 \\
\hline \multirow[t]{5}{*}{3} & \multicolumn{9}{|l|}{ Occupation of mother } \\
\hline & Professionals & 0 & 0 & 0 & 0 & 0 & 0 & 0 & 0 \\
\hline & $\begin{array}{l}\text { Plant \& machine operators \& } \\
\text { assemblers }\end{array}$ & 0 & 0 & 0 & 0 & 6 & 20 & 6 & 6.66 \\
\hline & Elementary occupation & 4 & 13.3 & 1 & 3.333 & 0 & 0 & 5 & 5.556 \\
\hline & Unemployed & 26 & 86.7 & 29 & 96.67 & 24 & 80 & 79 & 87.78 \\
\hline \multirow[t]{4}{*}{4} & Parity & & & & & & & & \\
\hline & \begin{tabular}{|l|} 
Primi \\
\end{tabular} & 17 & 56.7 & 6 & 20 & 13 & 43.33 & 36 & 40 \\
\hline & \begin{tabular}{|l|} 
Multi \\
\end{tabular} & 11 & 36.7 & 14 & 46.67 & 12 & 40 & 37 & 41.11 \\
\hline & Grand multipara & 2 & 6.67 & 10 & 33.33 & 5 & 16.67 & 17 & 18.89 \\
\hline \multirow[t]{4}{*}{5} & Gap between pregnancies & & & & & & & & \\
\hline & $0-1$ year & 2 & 15.4 & 1 & 4.167 & 2 & 11.76 & 5 & 9.259 \\
\hline & $1-2$ year & 5 & 38.5 & 11 & 45.83 & 8 & 47.06 & 24 & 44.44 \\
\hline & $\geq 2$ year & 6 & 46.2 & 12 & 50 & 7 & 41.18 & 25 & 46.3 \\
\hline \multirow[t]{3}{*}{6} & Future desire for child & & & & & & & & \\
\hline & Yes & 18 & 60 & 5 & 16.67 & 13 & 43.33 & 36 & 40 \\
\hline & No & 12 & 40 & 25 & 83.33 & 17 & 56.67 & 54 & 60 \\
\hline \multirow[t]{3}{*}{7} & Previous contraception & & & & & & & & \\
\hline & Yes & 7 & 23.3 & 4 & 13.33 & 1 & 3.333 & 12 & 13.33 \\
\hline & No & 23 & 76.7 & 26 & 86.67 & 29 & 96.67 & 78 & 86.67 \\
\hline \multirow[t]{5}{*}{8} & Religion & & & & & & & & \\
\hline & Hindu & 27 & 90 & 30 & 100 & 27 & 90 & 84 & 93.33 \\
\hline & Muslim & 3 & 10 & 0 & 0 & 3 & 10 & 6 & $6 . .44$ \\
\hline & Christian & 0 & 0 & 0 & 0 & 0 & 0 & 0 & 0 \\
\hline & Other & 0 & 0 & 0 & 0 & 0 & 0 & 0 & 0 \\
\hline
\end{tabular}

Total 90 samples as per the categories mentioned in Table 1 were recruited for the study. Majority of the samples (46.67\%) belonged to age group of 20-24 years. Majority of the samples $(70 \%)$ had completed education only up to middle school or less than that, showing literacy rate in DNH is less \& therefore majority of the samples $(87.78 \%)$ were unemployed. $41.11 \%$ of samples were multi para whereas $18.89 \%$ of samples were grand multi, out of which majority of samples (53.7\%) had gap between two pregnancy 0 -2 years showing that recommended interval between two pregnancies were not being maintained. Majority of the samples (86.67\%) did not use any kind of contraception, shows either poor awareness or acceptability of various contraceptive methods. Majority of the samples (93.33\%) belonged to Hindu religion whereas $6.44 \%$ belonged to Muslim religion.

Table 2 Awareness about PPIUCD

\begin{tabular}{|c|c|c|c|c|c|c|c|c|c|}
\hline Sr. No. & Variable & \multicolumn{2}{|c|}{ Antenatal mothers } & \multicolumn{2}{|c|}{$\begin{array}{l}\text { Post natal mothers } \\
\text { undergone normal delivery }\end{array}$} & \multicolumn{2}{|c|}{$\begin{array}{l}\text { Post natal mothers } \\
\text { undergone LSCS }\end{array}$} & \multicolumn{2}{|l|}{ Total } \\
\hline \multirow[t]{4}{*}{1} & & $\mathrm{n}=30$ & & $\mathrm{n}=30$ & $\%$ & $\mathrm{n}=30$ & $\%$ & $\mathrm{n}=90$ & $\%$ \\
\hline & Äwareness about PPIUCD & & & & & & & & \\
\hline & Yes & 8 & 26.7 & 11 & 36.67 & 2 & 6.667 & 21 & 23.33 \\
\hline & No & 22 & 73.3 & 19 & 63.33 & 28 & 93.33 & 69 & 76.67 \\
\hline
\end{tabular}

Table 2 shows that majority of the samples (76.67\%) were not aware of PPIUCD. In present study, the counseling \& education related to PPIUCD, its advantages - disadvantages were given to all the samples on first day of meeting. On day 2, data mentioned in Table $3 \& 4$ were collected. 
Table 3 Readiness for PPIUCD insertion

\begin{tabular}{|c|c|c|c|c|c|c|c|c|c|}
\hline Sr. No. & Variable & $\begin{array}{l}\text { Anteno } \\
\text { mother }\end{array}$ & & \begin{tabular}{|l} 
Post no \\
deliver
\end{tabular} & hers undergone normal & $\begin{array}{l}\text { Post na } \\
\text { underg }\end{array}$ & $\begin{array}{l}\text { tal mothers } \\
\text { yone LSCS }\end{array}$ & Total & \\
\hline 1 & & $\mathrm{n}=30$ & $\%$ & $\mathrm{n}=30$ & $\%$ & $\mathrm{n}=30$ & $\%$ & $\mathrm{n}=90$ & $\%$ \\
\hline & $\begin{array}{l}\text { Readiness for PPIUCD } \\
\text { insertion }\end{array}$ & & & & & & & & \\
\hline & \begin{tabular}{|l|} 
Yes \\
\end{tabular} & 12 & 40 & 6 & 20 & 2 & 6.667 & 20 & 22.22 \\
\hline & No & 18 & 60 & 24 & 80 & 28 & 93.33 & 70 & 77.78 \\
\hline
\end{tabular}

Table 3 shows that majority of the samples (77.78\%) had shown their unwillingness for insertion of PPIUCD. Here, it had been noticed that if counseling \& education about PPIUCD are given during antenatal period (at term) before labor starts, the level of acceptance can be more improved after delivery than giving counseling \& education after vaginal delivery or CS.

Table 4 Factors associated with non-acceptance

\begin{tabular}{|c|c|c|c|c|c|c|c|c|c|}
\hline \multirow[t]{2}{*}{ SrNo } & \multirow[t]{2}{*}{ Variable } & \multicolumn{2}{|c|}{$\begin{array}{c}\text { Antenatal } \\
\text { mothers }\end{array}$} & \multicolumn{2}{|c|}{\begin{tabular}{|c|}
$\begin{array}{c}\text { Post natal mothers } \\
\text { undergone normal } \\
\text { delivery }\end{array}$ \\
\end{tabular}} & \multicolumn{2}{|c|}{$\begin{array}{c}\text { Post natal } \\
\text { mothers } \\
\text { undergone LSCS }\end{array}$} & \multicolumn{2}{|c|}{ Total } \\
\hline & & $\mathrm{n}=30$ & $\%$ & $\mathrm{n}=30$ & $\%$ & $\mathrm{n}=30$ & $\%$ & $\mathrm{n}=90$ & $\%$ \\
\hline 1 & Refusal by relatives & 8 & 44.44 & 10 & 41.66 & 10 & 35.71 & 28 & 40 \\
\hline 2 & Wants to discuss with family members & 10 & 55.55 & 3 & 12.5 & 7 & 25 & 20 & 28.57 \\
\hline 3 & Prefers to use natural methods & 6 & 33.33 & 6 & 25 & 3 & 2 & 15 & 21.43 \\
\hline 4 & Fear of obesity & 4 & 22.22 & 6 & 25 & 5 & 17.85 & 15 & 21.43 \\
\hline 5 & Fear of pain and heavy bleeding & 3 & 16.66 & 1 & 4.16 & 9 & 32.14 & 13 & 18.57 \\
\hline 6 & Refusal by partner & 4 & 22.22 & 6 & 25 & 3 & 10.71 & 13 & 18.57 \\
\hline 7 & Not having enough experience of PPIUCD & 8 & 44.44 & 5 & 20.83 & 0 & 0 & 13 & 18.57 \\
\hline 8 & $\begin{array}{l}\text { Satisfied with contraceptive methods used } \\
\text { previously }\end{array}$ & 4 & 22.22 & 2 & 8.3 & 5 & 17.85 & 11 & 15.71 \\
\hline 9 & Does not want contraception immediately & 2 & 11.11 & 3 & 12.5 & 4 & 14.28 & 9 & 12.86 \\
\hline 10 & Fear of insertion & 2 & 11.11 & 3 & 12.5 & 3 & 10.71 & 8 & 11.43 \\
\hline 11 & Fear of effect to future fertility & 7 & 38.88 & 0 & 0 & 1 & 3.57 & 8 & 11.43 \\
\hline 12 & Fear of cancer & 3 & 16.66 & 1 & 4.16 & 3 & 10.71 & 7 & 10 \\
\hline 13 & Fear of expulsion & 3 & 16.66 & 0 & 0 & 3 & 10.71 & 6 & 8.57 \\
\hline 14 & Interferes with sexual intercourse & 2 & 11.11 & 3 & 12.5 & 1 & 3.57 & 6 & 8.57 \\
\hline 15 & Religious beliefs & 2 & 11.11 & 1 & 4.16 & 3 & 10.71 & 6 & 8.57 \\
\hline 16 & Wants to use lactational amenorrhea method & 3 & 16.66 & 0 & 0 & 2 & 1 & 5 & 7.14 \\
\hline 17 & Previous bad experience & 0 & 0 & 0 & 0 & 0 & 0 & 0 & 0 \\
\hline 18 & Infrequent sex & 0 & 0 & 0 & 0 & 0 & 0 & 0 & 0 \\
\hline
\end{tabular}

Table 4 shows factors associated with non-acceptance of PPIUCD. The results revealed that majority of the samples (40\%) reported refusal from relatives (mainly mother, sister \& mother in law) whereas $18.57 \%$ of the samples reported refusal from partner.

All Muslim women reported that their religion doesn't permit them. $28.57 \%$ women said that they want to discuss with family members which shows that counseling about PPIUCD should be given during antenatal period itself so that kind of delay for making decision can be avoided. $21.43 \%$ women preferred to use natural method out of which $7.14 \%$ preferred to use lactational amenorrhea method. $21.43 \%$ women had fear of obesity. The other factors reported were fear of pain and heavy bleeding (18.57\%), refusal by partner (18.57\%), not having enough experience of PPIUCD (18.57\%), satisfied with contraceptive methods used previously (15.71\%), do not want contraception immediately (12.86\%), fear of insertion (11.43\%), fear of effect to future fertility ( $11.43 \%)$, fear of cancer ( $10 \%)$, fear of expulsion (8.57\%) and interferes with sexual intercourse (8.57\%). No one reported previous bad experience or infrequent sex as the responsible factors for non-acceptance.

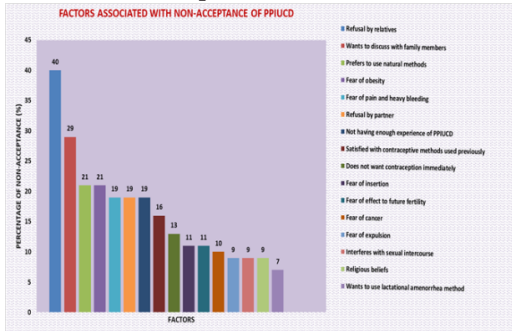

Figure 1 Factors associated with non-acceptance

\section{DISCUSSION}

In the study, it is found that the overall awareness regarding PPIUCD in the study population is only $23.33 \%$ which is comparable with the study findings of Rajasthan where the awareness was $20.2 \% .^{8}$ The readiness rate for PPIUCD insertion after the counselling in present study was $22.22 \%$ which is higher than the study report from Government Medical College, Trissur, Kerala where the acceptance rate was $10.5 \%$. ${ }^{1}$ The major factors associated with nonacceptance were refusal by relatives $(40 \%)$ and need to discuss with formily members $(28.57 \%)$. These findings are comparable with the study results from the tertiary care centers of Andhra Pradesh in which the common causes for refusal of PPIUCD was the negative thoughts of parents and relatives (60\%). This gives us a clear hint for the need of public awareness regarding the programme through different medias along with the individual counselling sections of the couples.

\section{CONCLUSION}

Dadra \& Nagar Haveli is a tribal dominated district of the union territory. It has been noticed that $60 \%$ women are educated only up to Middle School. The prior knowledge of PPIUCD was very low (23.33\%) \& the acceptance of PPIUCD after counseling was also low (22.22\%). Therefore due attention should be given to the education level of women \& effective PPIUCD counseling should be given during antenatal visits itself to enhance the acceptance among women as more acceptance of PPIUCD had been seen among the category of term antenatal mothers in the present study. Integration of a PPIUCD counseling service at every delivery point with provision of couple counseling will improve the 
success of this programme. There is a need to educate the women of the district along with their families. A need was also seen to educate the faith based organizations, specially the Muslim faith based organizations. A definitive plan of education \& counselling need to be incorporated for each sections of the society. This may play a pivot role to meet unmet need of contraception in D\&NH.

\section{REFERENCES}

1. ALUKAL Anila Tresa; RAVEENDRAN Resmy C. GEORGE Lissiamma. PPIUCD: awareness and reasons for non-acceptance. International Journal of Reproduction, Contraception, Obstetrics and Gynecology, [S.l.], v. 7, n. 2, p. 582-586, jan. 2018. ISSN 2320-1789. Available at: <https:// www. ijrcog. org/ index.php/ijrcog/article/view/4057> . Date accessed: 09 nov. 2020. doi: http:// dx.doi.org/10.18203/2320-1770.ijrcog20180176.

2. Doley R, Pegu B. A retrospective study on acceptability and complications of PPIUCD insertion. J. Evolution Med. Dent. Sci. 2016;5(31):1631-1634, DOI: $10.14260 /$ jemds/2016/384

3. Dr.R.VidyaRama, Dr.T.Nagamani, Dr.Prasad Usha Ppiucd As A Long Acting Reversible Contraceptive (Larc) - an Experience at A Tertiary care Centre, IJSR - International Journal Of Scientific Research, Volume : 4 |,Issue : 5, May 2015 ISSN No 2277-8179

4. Family Planning Division Ministry of Health and Family Welfare Government of India, Reference Manual for IUCD Services(March 2018), https:// nhm. gov. in/ New Updates 2018/NHM Components RMNCHA Family planning/ Schemes \& Guidelines/IUCD/IUCD Manual English.pdf

5. Family Planning Division Ministry of Health and Family Welfare Government of India, Postpartum IUCD Reference Manual(November 2010), https:// nhm.gujarat.gov.in/Portal/SSP/manual l ppiucd-reference-manual.pdf

6. Gonie, A., Worku, C., Assefa, T. et al. Acceptability and factors associated with post-partum IUCD use among women who gave birth at bale zone health facilities, Southeast-Ethiopia. Contracept Reprod Med 3, 16 (2018). https://doi.org/10.1186/s40834-018-0071-z.

7. Pradeep MR, Nayana DH. Study of knowledge, attitude and acceptance of PPIUCD in antenatal mothers. The New Indian Journal of OBGYN. 2019; 6(1): $42-4$.

8. SHARMA, Ashutosh; GUPTA, Vinita. A study of awareness and factors affecting acceptance of PPIUCD in South-East Rajasthan. International Journal Of Community Medicine And Public Health, [S.l.], v. 4, n. 8, p. 27062710, july 2017. ISSN 2394-6040. Available at: <https:// www. ijcmph. com/index.php/ijcmph/article/view/1758>. Date accessed: 09 nov. 2020. doi:http://dx.doi.org/10.18203/2394-6040.ijcmph20173313. 